\title{
A framework for evaluation of existing pavement conditions and selection of feasible maintenance/rehabilitation alternatives; a case study in some routes of Livingston Parish in the state of Louisiana
}

\author{
Hossein Alimohammadi ${ }^{1}[$
}

Received: 12 October 2019 / Accepted: 8 January 2020 / Published online: 29 January 2020

(c) Springer Nature Switzerland AG 2020

\begin{abstract}
This study presents a step-by-step framework process/general guideline for the process of project evaluation, identify, document, and evaluate the existing pavement conditions plus evaluate the most feasible maintenance/rehabilitation alternatives for flexible roads. The presented framework could be significantly useful for extending the service life of the pavement, based on their accurate time of application. The presented framework consists of six classified steps to evaluate the existing condition of the pavement, assessing the cost-effectiveness of different maintenance or rehabilitation techniques by conducting Life Cycle Cost Analysis and selecting feasible alternative techniques according to distress types in the flexible pavements. As of the framework, four existing pavements located in Livingston parish in the state of Louisiana have evaluated in detail. Finally, at least two feasible alternatives have suggested for each subsection roads and most cost-effective alternative techniques scored according to assigned weighting factors. Although Different strategies are using by various highway agencies to evaluate the strategy of selection of the appropriate alternative, which is different in the details, the proposed framework could evaluate the uncertainties associated with infrastructure conditions plus determining the optimal inspection, maintenance, and rehabilitation decision policies. This study presents that Micro-surfacing and thin overlay techniques found the most common techniques for the case studies sections, which are according to the Louisiana Department of Transportation and Development common treatment selection strategy.
\end{abstract}

Keywords Rehabilitation · Maintenance $\cdot$ Flexible pavement $\cdot$ Feasible alternative $\cdot$ Framework

\section{Introduction}

Pavement maintenance/rehabilitation is an important challenge faced by pavement engineers and highway administrations. Therefore, condition evaluation and performance assessment of the pavement is required to decide any required maintenance and rehabilitation in the appropriate time of application. Choosing the appropriate maintenance/rehabilitation method and strategy could develop ride comfort and traffic safety. Also, it lowers the costs of vehicle operation, as well as environmental/construction costs [1]. State transportation agencies across the country employ pavement evaluation and pavement management methods to keep roads in good condition, and to help extend pavement service life and reduce the overall life cycle cost [2]. Maintenance/rehabilitation works are used when the condition of the road surface becomes defective or poor and most often use to slow down or reset the deterioration process. Maintenance actions could decelerate the rate of deterioration in pavements.

Hossein Alimohammadi, hosseina@iastate.edu | ${ }^{1}$ Civil, Construction and Environmental Engineering, lowa State University, Ames, IA 50011, USA. 
On the other hand, rehabilitation could reset the deterioration process by repairing portions of an existing pavement [3]. Two key components of an overall pavement preservation program are preventive and corrective maintenance. In preventive maintenance, we are doing a task before a failure has occurred, but corrective maintenance could be the result of a deliberate run-to-failure strategy [4]. The Preventive maintenance actions depend on the distress types and levels, are commonly include: crack seal, fog seal, slurry seal, chip seal, thin overlay, and Micro-surfacing. The expected cost and survival life-lasting of these treatments are different based on their time of application and mainly performed from the Federal Highway Administration (FHWA) agency's observational experience and many other factors. For example, some treatments such as slurry seal, chip seal, thin overlay, and Micro-surfacing could control the appearance of distresses for almost 6 years (vary from 3 to 12 years depends on the country and applications). Also, it depends on the material used in the treatments and preparations; crack sealing could last up to 9 years. Besides, the application of these treatments is different. For an instant, the Micro-surfacing is recommended for minor leveling than for medium to high severity cracking, or the crack sealing is just appropriate to use when distresses like transverse/longitudinal cracks appear in low or medium severity in the pavements.

Although the procedures of selection the rehabilitation strategy used by the individual highway agencies differ in their details, they generally consist of: collection of data, evaluation of the pavement, selection of the appropriate rehabilitation techniques, the formation of rehabilitation strategies, life-cycle cost analysis, and then selection of one pavement rehabilitation strategy among the existing alternatives [5]. Pavement condition indicators, such as Pavement Condition Index (PCI), Pavement Quality Index (PQI), Present Serviceability Rating (PSR), and International Roughness Index (IRI), are some of the main components assumed by any Pavement Management System (PMS). An unbiased and repeatable survey procedure which are also easily understood and pretty simple to perform in the field is usually selected. Among the mentioned indicators above, the $\mathrm{PCl}$ procedure is the most commonly used technique which is developed by the U.S. Army Corps of Engineers in the 1970s [6]. The PCl evaluates both flexible and rigid pavements in which the evaluation procedure follows the MicroPAVER distress guide methodology [1]. It provides a measure of the surface conditions and rides quality, which is a composite index of structural integrity and functional conditions of the pavement. This method uses nineteen different distress types that incorporating their extent and severity. The PCI method is considered a Standard ASTM Test Method, named as ASTM D6433-11 [7]. PCI ranges from 0-100, which zero indicates poor/failed pavements and 100 excellent performing distress-free pavements.
Many researchers used the $\mathrm{PCl}$ method to measure pavement performance. For instance, Gallego et al. developed a methodology for evaluating the condition of rural roads by using 41 rural roads in Spain using $\mathrm{PCl}$ value as the most important index in the classification of the overall condition of the pavement [8]. McPherson and Muchnick studied the effect of tree shades on flexible pavements, using the collected PCI data for 48 street segments in California as the evaluation of the pavement's performance [9]. The $\mathrm{PCl}$ was used by Mishalani and Gong as well for the pavement condition variable in their developed decision-making framework in order to advance the inspection of spatial sampling decisions in the field of infrastructure management [10].

The selection of the most appropriate maintenance/rehabilitation treatments for its aging highway network is one of the top priorities in different agencies [11]. In the State of Louisiana, chip seal and Micro-surfacing are the most common preventive maintenance treatments developed by the agencies and according to NCHRP Project 1-38 [5]. However, a comprehensive framework/method that could address the distresses of the pavement and evaluate the required appropriate pavement maintenance/rehabilitation technique, which is straight forward, and cost-beneficial is still investigated by researchers to optimize and introduce to the designers and relative agencies for use in their projects.

This study provides a step-by-step framework and general guidelines for the process of project evaluation, identify, document, and evaluate the existing pavement conditions, plus selecting a feasible rehabilitation/maintenance for a case study of some roads in Livingston parish in Louisiana. Also, this study provides at least two feasible rehabilitation alternatives based on the historical information and field survey for each section. The proposed framework could evaluate the uncertainties associated with infrastructure conditions and forecasting optimal inspection, maintenance, and rehabilitation decision policies.

\section{Methodology}

In this study, four state routes with eleven subsections with a total length of $53 \mathrm{~km}$ (33 miles) flexible pavement as the main roads in the mentioned parish in the state were evaluated. Figure 1 depicts the state routes selected for pavement evaluation and analysis. The red routes in this picture were studied in this study. More details of each route and subsections provided in the tables in the following sections of this paper. In this study, six steps were followed in the project evaluation and selection of feasible maintenance/rehabilitation alternatives process [5], [12], which illustrated in Fig. 2. In the first step, collection and analyzing were performed by utilizing the 
Fig. 1 Selected state routes for pavement evaluation and analysis [14]
Step 1: Collection of historical data from PMS

Step 2: Pavement distress and drainage surveys

Step 3: pavement evaluation based on trigger values

Fig. 2 Six steps were followed in the project evaluation and selection of feasible maintenance/rehabilitation alternatives process
Step 4: Analyzing the data and determining the Feasible Alternatives

Step 5: Life Cycle Cost Analysis (LCCA) and Ranking of Feasible Alternatives

Step 6: Selection of Feasible

Alternative

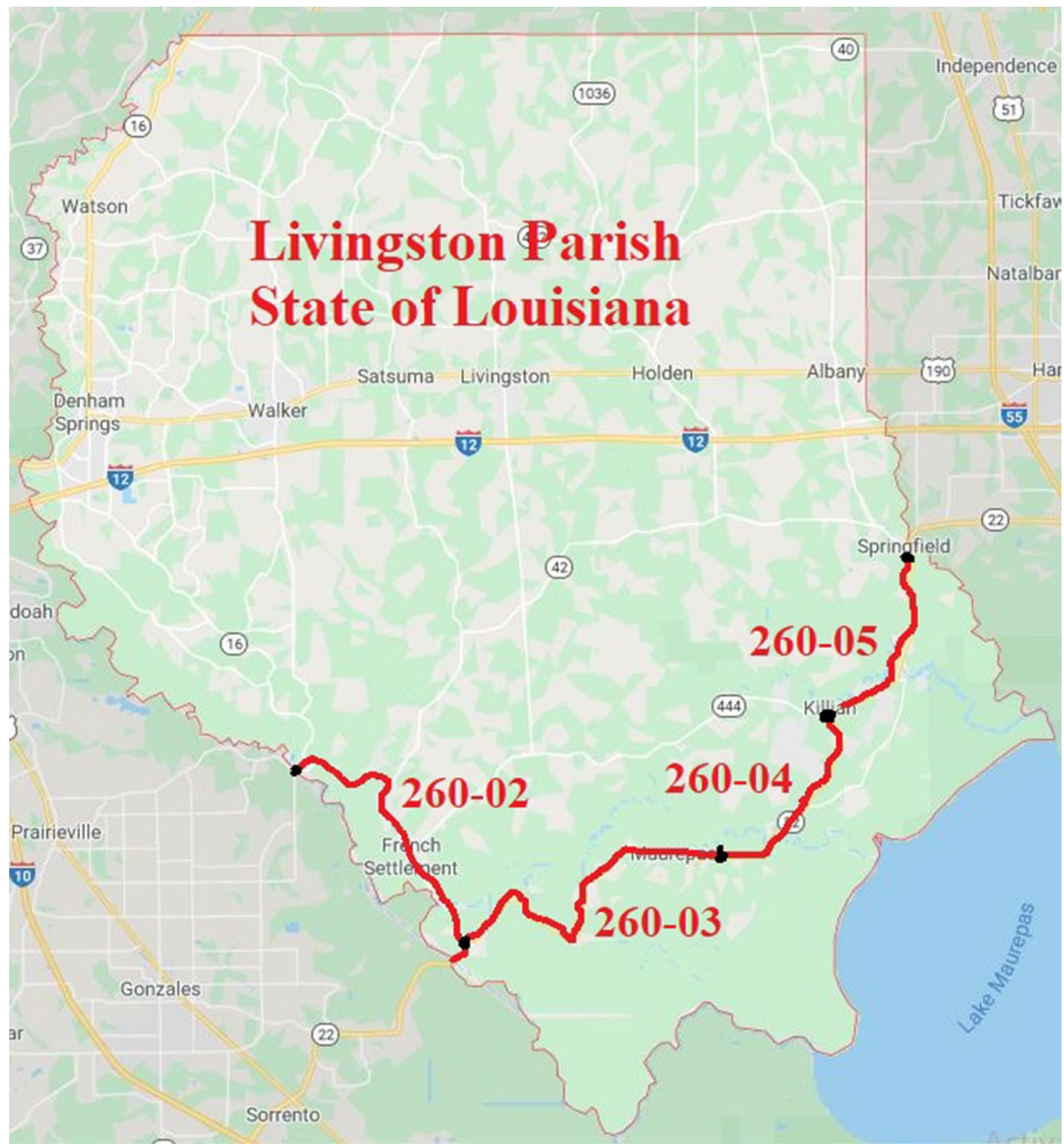

Pavement Management System (PMS) data available from the Louisiana Department of Transportation and Development (LaDOTD) database. The second step was pavement distress and drainage surveys. In the third step, pavement evaluation was conducted based on trigger values. Table 1 illustrates the trigger values used in this study and currently used by LaDOTD for treatment selection and decision-making. This matrix used by LADOTD PMS generally is based on the surface distress indices plus the highway functional class (such as interstate,

Table 1 LaDOTD trigger values for rehabilitation strategies [15]

\begin{tabular}{|c|c|c|c|c|c|}
\hline Description & Alligator & Random & Patch & RUT & Roughness \\
\hline Micro-surfacing on arterial & $>=95$ & $>=95$ & $>=95$ & $>=65<90$ & $>=80$ \\
\hline \multirow[t]{2}{*}{ Thin overlay on arterial (cold plane 2", put 2" back; 0-100 sq.yd. Patching) } & $>=80$ & $>=80$ & $>=80$ & $<65$ & $>=70$ \\
\hline & $<90$ & $<95$ & & & $<90$ \\
\hline $\begin{array}{l}\text { Medium Overlay on Arterial (Cold Plane } 2 " \text {, put } 3.5^{\prime \prime} \text { back or just 3.5" over- } \\
\text { lay, } 100-300 \text { sq.yds Patching) }\end{array}$ & $\begin{array}{l}>=60 \\
<80\end{array}$ & $<80$ & $\begin{array}{l}>=60 \\
<80\end{array}$ & - & $<70$ \\
\hline Structural overlay on arterial (5.5" Overlay; 700 sq.yds. Patching) & $<60$ & - & $<60$ & - & - \\
\hline
\end{tabular}


arterial, and collector) [13]. Then a developed framework for pavement evaluation was conducted to analyze the data and determine the most feasible maintenance treatments among several candidate's rehabilitation treatments in the fourth step. Finally, the recommended alternative that could address problems, most cost-effective solution, and could satisfy project constraints were chosen for each case sections in the last step.

The rehabilitation strategy selection procedures used by the individual highway agencies, such as FHWA, National Highway Traffic Safety Administration (NHTSA), National Highway Traffic Safety Administration (NHTSA), and so on [5] varies in their details but typically consist of steps mentioned above. This study provides a step-bystep process and guidelines for each of these activities.

\subsection{Collection of historical data from PMS}

The first step in the rehabilitation process is the collection of historical data, which collected from the LaDOT PMS database in this study. Table 1 presents the thresholds and trigger values currently used by LADOTD for treatment selection plus decision making [13].

Generally, PMD data consists of traffic data (both present and past data) pavement distress information over the years, environmental conditions, existing subgrade capacity, etc. It consists of an extensive database, including pavement, distresses, and performance data for each state highway separately [13].

From PMS data, we can also find out the historical construction, design, and maintenance information. Types of distresses that considered in this section include rutting, roughness, fatigue cracking, longitudinal cracking, and random cracking.

\subsection{Pavement distress and drainage surveys}

As the historical data collection didn't provide complete insight into the existing pavement condition, the Primary field survey was performed in this step to get insight on the pavement condition. A pavement distress survey was performed to identify visible distress and evaluate the overall pavement condition. A combination of windshield survey, shoulder survey, and walking the project, without any traffic control (with the appropriate safety attire) were conducted to gather the above information [16]. The overall drainage condition of the pavements was determined from the drainage survey, as the poor drainage adversely affects both structural and functional performance of the pavement. The information from the drainage survey was used to determine any moisture-related distress if present. Figure 3 shows some field survey pictures performed in the team site visits and clearly illustrates the drainage collector systems, and some mentioned relative potential reasons that could cause future distresses in the pavements.

\subsection{Pavement evaluation and pavement maintenance/rehabilitation trigger values}

The data collected from previous steps were utilized to assess the current conditions of the pavement and the selection of alternative treatment methods. Pavement prediction models, along with the trigger values, are used to determine the structural and functional performance of the pavement plus determining the various maintenance and rehabilitation strategies [17] One of the widely used trigger factors is the Pavement Condition Index (PCI),
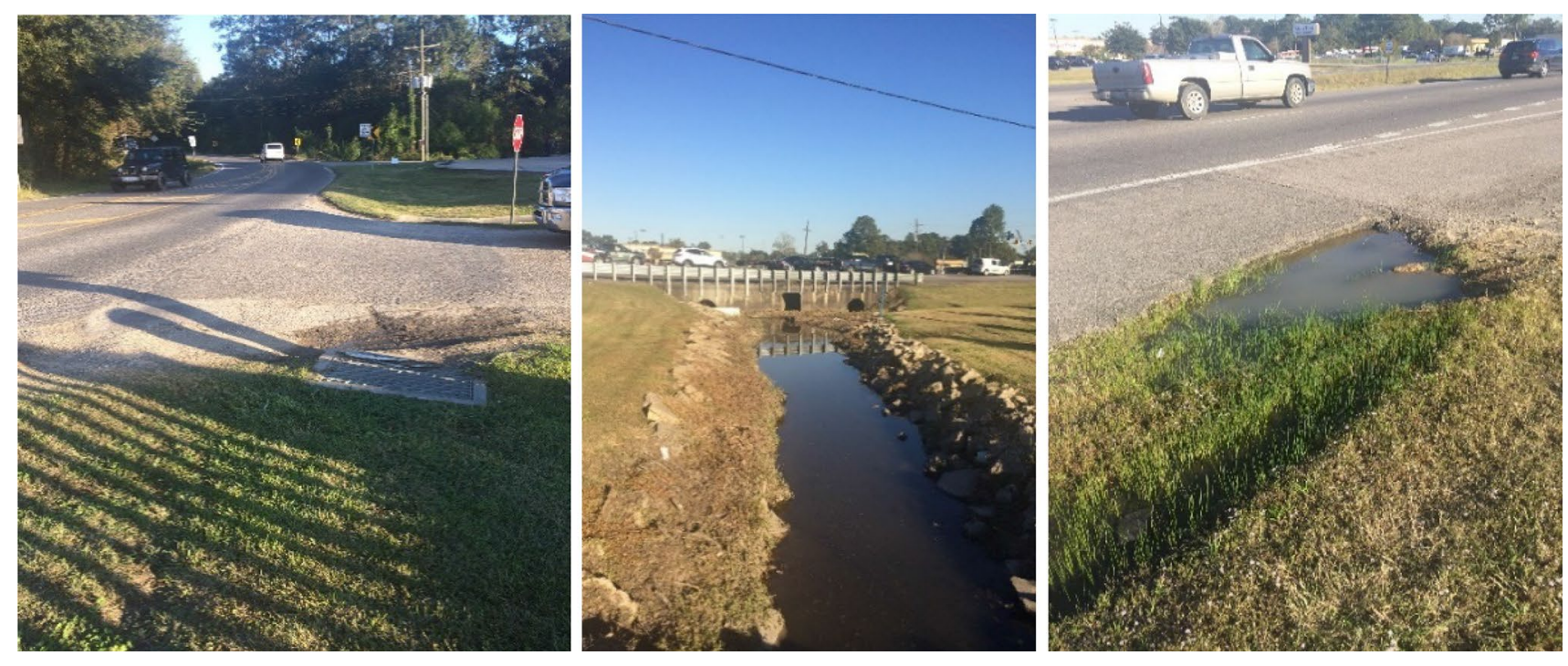

Fig. 3 Field survey performed in this study

\section{SN Applied Sciences}




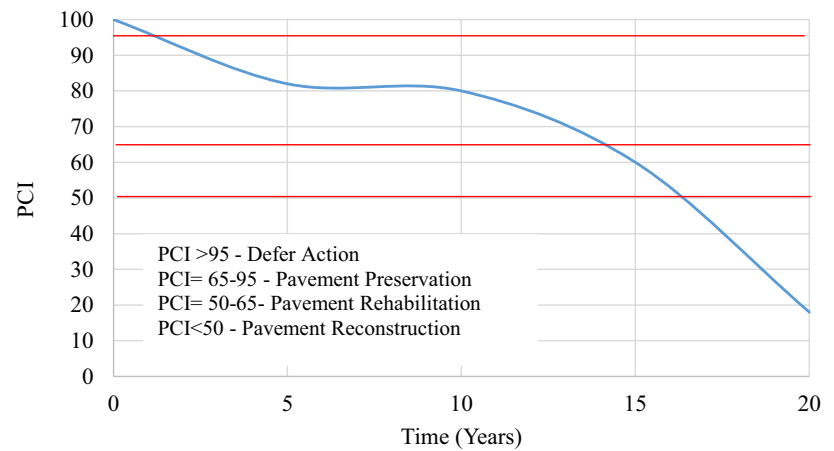

Fig. $4 \mathrm{PCI}$ Trigger values used in the analysis [21]

which scaled from 0 to 100 . For flexible pavements, $\mathrm{PCl}$ is calculated by Eq. (1) [5]:

$P C l=\max (\min (R N D M, A L C R, P T C H, R U F F, R U T)$,

$$
\begin{aligned}
& \{A V G(R N D M, A L C R, P T C H, R U F F, R U T)-0.85 S T D \\
& (R N D M, A L C R, P T C H, R U F F, R U T)\})
\end{aligned}
$$

where RNDM is a random cracking index, ALCR is an alligator cracking index, PTCH is patch index, RUFF is roughness index, RUT is rutting index, and STD is a standard deviation.

A series of inspections were conducted using the $\mathrm{PCl}$ survey procedure documented in the publications of $F A A$ Advisory Circular (AC) 150/5380-6C, FAA AC 150/5380-7B, and ASTM D5340-12. The results of a PCl evaluation indicate the structural integrity and functional capabilities of the pavement [18], and consequently, the Eq. 1 became the most popular equation that is using for the pavement evaluation in the state [5]. The critical PCl defined as the value at which $\mathrm{PCl}$ loss rate increases significantly with time. Figure 4 represents the selected $\mathrm{PCl}$ for this study. From Fig. 4, it can be stated that the critical PCl selected for this study is below 50, which means the pavement is in poor condition and requires reconstruction. For $\mathrm{PCl}$, over 65 means the pavement condition is fair [19]. When the $\mathrm{PCl}$ value is between 50 and 65 , rehabilitation treatment is suggested. For pavements with $\mathrm{PCl}$ value between 65 and 95 preventative, maintenance treatment is required, and for the pavement with $\mathrm{PCl}$ value greater than 95 , no action (i.e., defer action) is suggested [20].

\subsection{Analyze the data and determine feasible alternatives}

Based on the trigger values and the collected data, different feasible alternatives were selected for each subsection. The alternatives were suggested based upon the distress present, current $\mathrm{PCl}$, drainage condition, and severity of the distress.
Table 2 Typical Unit Cost and Expected Life of Typical Pavement Maintenance [23]

\begin{tabular}{lll}
\hline Treatment type & $\begin{array}{l}\text { Unit Cost per Lane } \\
\text { mile }\end{array}$ & $\begin{array}{l}\text { Average } \\
\text { expected life } \\
\text { (Years) }\end{array}$ \\
\hline Thin lift overlay & $\$ 201,015$ & 10 \\
Structural overlay & $\$ 274,912$ & 11 \\
Ultra-thin overlay & $\$ 52,009$ & 9 \\
Cold planning HMA & $\$ 16,353$ & - \\
Crack sealing & $\$ 8501$ & 3 \\
Fog seals & $\$ 7651$ & 3 \\
Slurry seal & $\$ 15,302$ & 5 \\
Micro-surfacing & $\$ 58,071$ & 6 \\
Chip seal & $\$ 11,998$ & 5 \\
Patching & $\$ 44,670$ & 6 \\
Sand seal & $\$ 26,473$ & 3.5 \\
Scrub seal & $\$ 19,318$ & 5 \\
Cape seal & $\$ 29,922$ & 7 \\
\hline
\end{tabular}

\subsection{Life cycle cost analysis (LCCA) and ranking of feasible alternatives}

The maintenance and rehabilitation costs used for the analysis in this study were determined from different sources by previous studies [19], [22], such as the Department of Agriculture [23], Federal Highway Administration (FHWA) [24], and LADOTS PMS database. Table 2 indicates the unit cost and expected performance life of different maintenance and rehabilitation techniques collected from the mentioned sources [19], [22], [23].

LCCA, which is based on a cradle-to-grave framework, determines the total cost of pavement, including initial costs, rehabilitation and maintenance, and end-of-life as well when different feasible alternatives are available for the same section of pavement. LCCA is used at a project level as a decision-making tool to select a cost-effective alternative among different pavement alternatives. On the other hand, LCCA is used at a network-level in the prioritization of pavement needs for the future.

The life-cycle cost of pavement could be estimated by two different approaches, deterministic and probabilistic [25]. This project adopted the deterministic approach and determined the Present Net Value (NPV) of each feasible alternative. In this project, Present Worth (PW) is calculated by discounting all project costs to a base year (i.e., 2018). By using Eq. 2, all the project costs throughout the analysis period (30 years) are expressed in a single present year monetary value for all alternatives. The single representative cost value of various alternatives can then be directly compared. 
$P W=(F C) \frac{1}{\left[(1+i)^{n}\right]}$

where PW is present worth, FC is future cost, $\mathrm{i}$ is the interest rate, ( $5 \%$ adopted this study), and $\mathrm{n}$ is analysis period time (20 years for this study).

A set of different factor categories according to performance evaluation attributes, constructability attributes, and customer satisfaction attributes [19] are selected and converted into a set of weights, reflecting their relative importance in pavement rehabilitation and evaluation. The weighted categories were expected performance life (20\%), pavement structure (10\%), existing conditions (10\%), Initial cost (20\%), life cycle cost $(20 \%)$, Traffic Disruption (10\%), and Ease of Construction (10\%) in this study that illustrated as total score in the Tables 4, 6,8 , and 10 in the following sections of this study.

\subsection{Selection of feasible alternative}

The final step in project evaluation is the ranking of alternatives based upon the total weighted score and selecting the feasible alternative based on the alternative with the highest score that ranked as one, which is the most feasible strategy for maintenance/rehabilitation.

\section{Results}

In this part, the results were conducted for each selected route and subsections separately according to the mentioned steps for pavement evaluation.

\subsection{Control section 260-02}

From PMS data, Control Section 260-02 is flexible pavement consisted of sub-sections from 1 to 4 . This control section has an 8.777 total mile length. The different indices are included the cracking, rutting, ride, and friction. The Cracking Index is a combination of cracking data (such as longitudinal, transverse, and alligator cracking indices). Ride, and rutting indices utilize the International Roughness Index (IRI), plus rut depth, respectively [26]. Several items such as $\mathrm{PCl}$, Alligator index, Random index, Rut index, Roughness index, Average Daily Traffic (ADT) were collected. Table 3 shows these historical data for the year 2017, along with the considered sub-sections, log miles, and section length.

Figure 5 illustrates existing roadway photographs for the control section and the distresses that could capture from the performed site visit. Figure 6 shows the deteriorated pavement condition in terms of alligator cracking along the road sections that could be used for the sake of evaluations. From Fig. 6 , it can be found that the road received previous treatment in 1998 and 2005 for the

Table 3 PMS Data for Control Section 260-02

\begin{tabular}{lllllllllll}
\hline Sub-S. & Pave type & Lane mile & ADT & Rut index & Alligator index & Random index & Roughness index & PCl & Last year Rehab & Last rehab \\
\hline 1 & ASP & 5.66 & 5600 & 90.37 & 75.22 & 81.07 & 88.88 & 79.39 & 2005 & PST \\
2 & ASP & 1.85 & 5600 & 95.07 & 99.15 & 98.35 & 75.8 & 82.98 & 2005 & Hot mix \\
3 & ASP & 0.18 & 7700 & 88.22 & 74.02 & 84.12 & 77.11 & 76.84 & 2005 & medium \\
4 & ASP & 0.877 & 7700 & 93.36 & 83.5 & 85.8 & 75.05 & 78.77 & 2005 & overlay \\
\hline
\end{tabular}
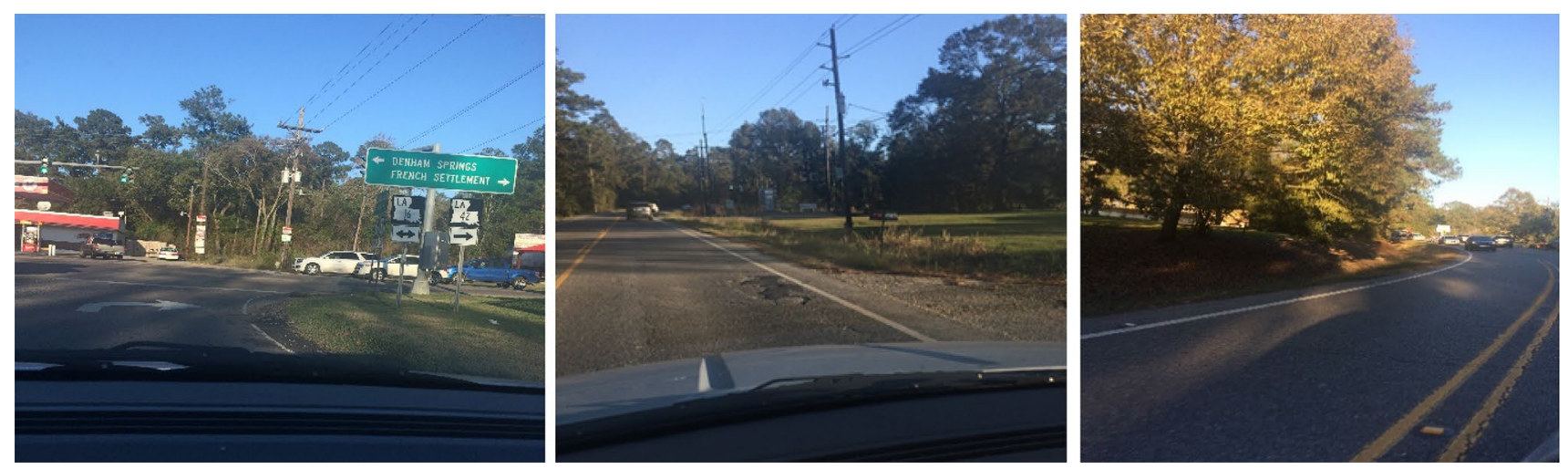

Fig. 5 Existing road conditions of LA 16 and LA 42

\section{SN Applied Sciences}




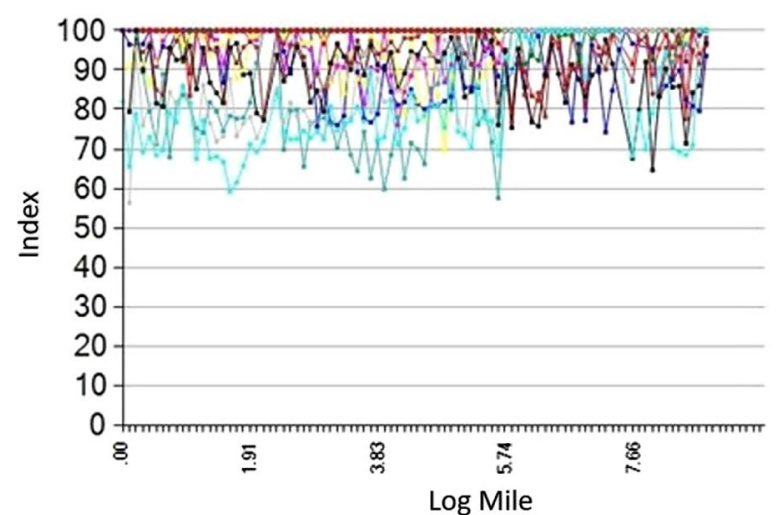

(a)

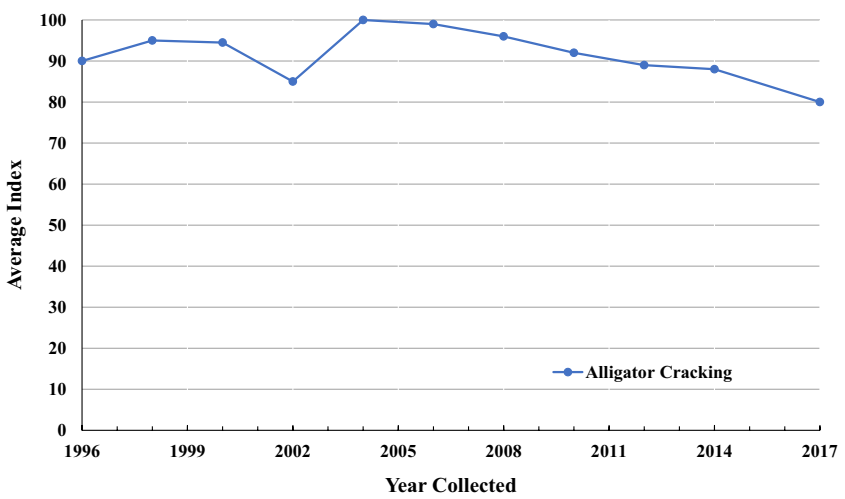

(b)

Fig. 6 Alligator index plot for control Section 260-02 Index plot in log Mile b Yearly average
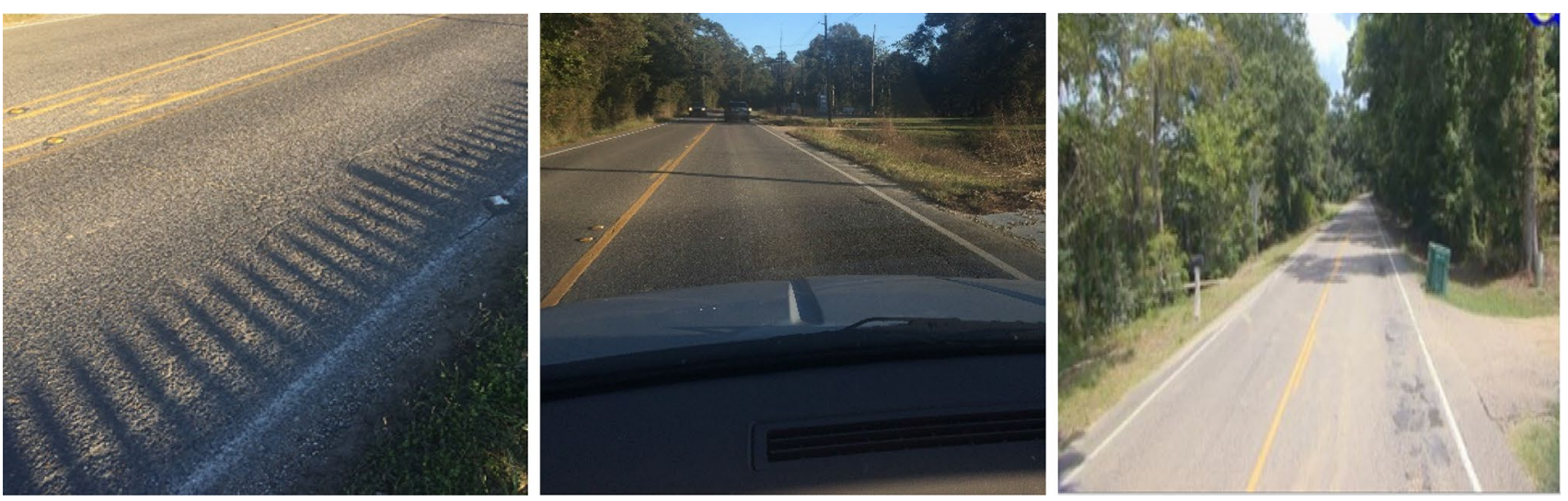

Fig. 7 Existing road conditions of LA 22

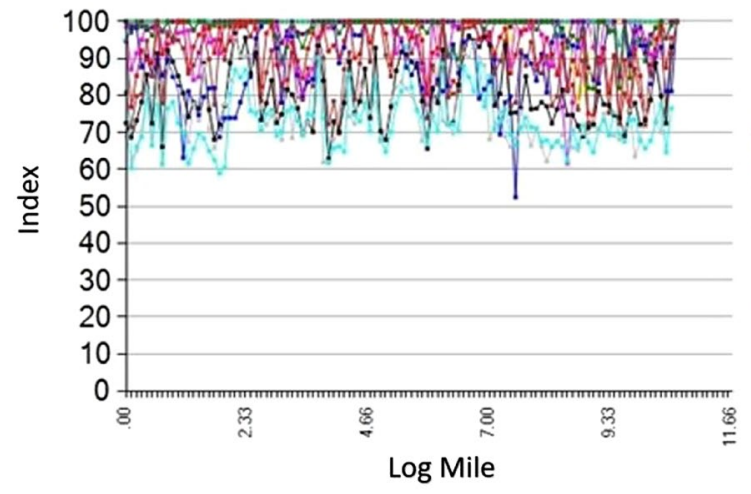

(a)

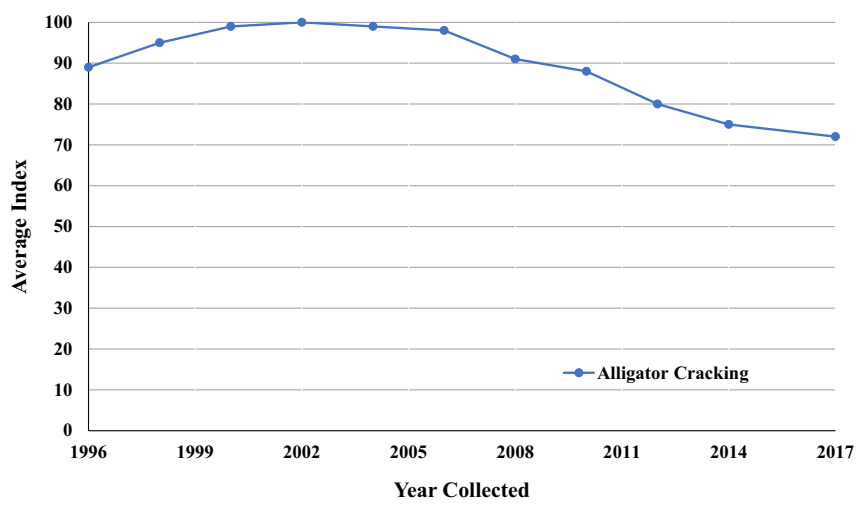

(b)

Fig. 8 Alligator index plot for LA 22 a index plot along mile route b Yearly average index plot 
alligator issue proposes in the route section. It seems that the alligator cracking index is decreasing after the last received treatment in 2005 , and also the decreasing situation for random and roughness issues is the same during the time.

\subsection{Control section $260-03$}

Control Section 260-03 is flexible pavement consisted of one subsection and has 10.615 total mile length. Like the previous section, several items were collected for the study in this section too.

Table 5 depicts PMS data and other information of this subsection for the year 2017.
Figure 7 shows the existing road condition photographs and some major alligators, roughness, and random cracking distresses in this section road. As expected, Fig. 8 clearly shows that the alligator index dropped down each year after the last treatment received in 2005, and the section requires to be corrected to preserve its design life. This Figure illustrates that roughness and random cracking is decreasing during the time as well.

\subsection{Control section 260-04}

This control section, the same as a previous control section, is flexible pavement and consists of one subsection and has 6.97 total mile length. Like the previous section,
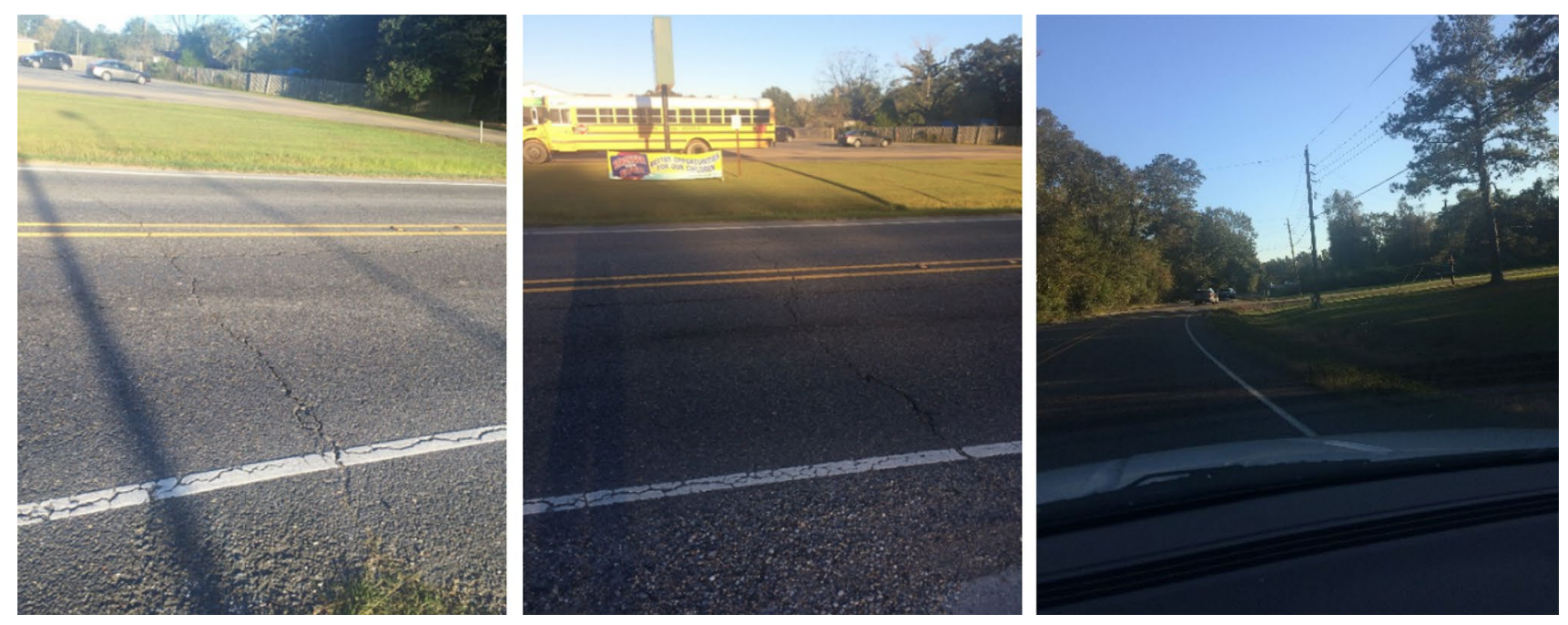

Fig. 9 Existing road conditions of LA 22

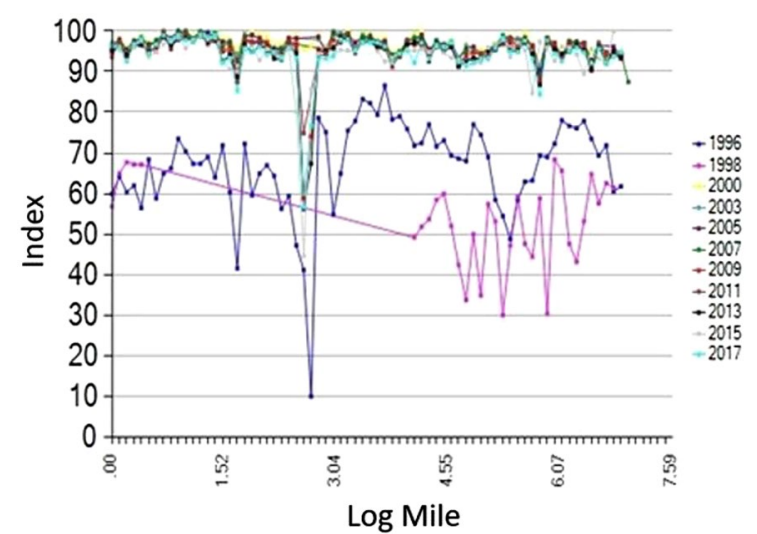

(a)

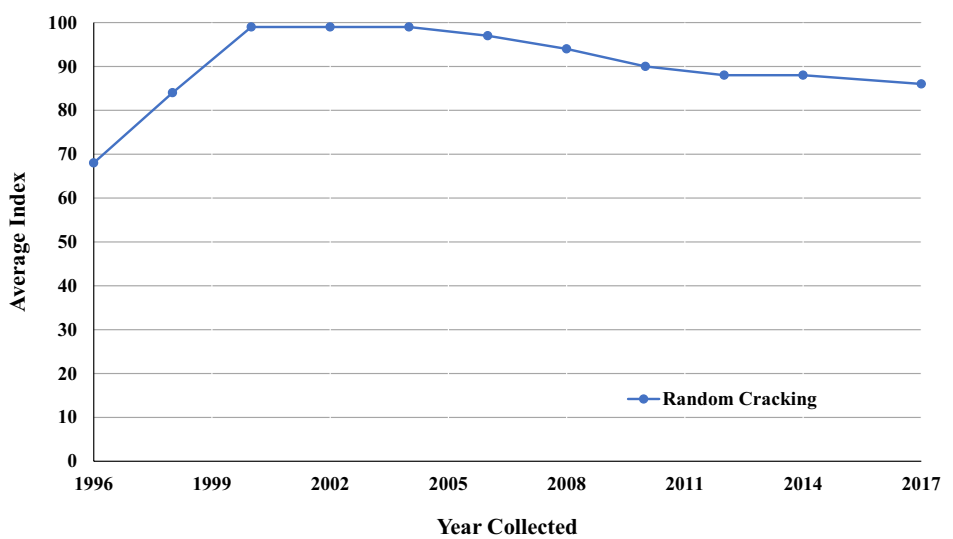

(b)

Fig. 10 Yearly average index plot for 260-04 a Roughness index b Random cracking index 
several items were collected for the study in this section too. Table 7 shows PMS and these historical data for the year 2017.

Figure 9 shows the existing roadway photographs for extensive random and transverse cracking existing in the control section. Also, from Fig. 10, it can be seen that roughness and random cracking are decreasing slightly after the last treatment received in the control section.

\subsection{Control section $260-05$}

Flexible pavement control Section 260-05 consisted of five subsections. Table 9 depicts PMS data of this control section for the year 2017,

Figure 11 shows the existing road conditions and some points in the road that have extensive roughness distresses in this section and Fig. 12 shows the roughness index for the control section between the years 1996 and 2017 to provide better insight into the nature of roughness. Figure 12 shows that in 2007, the road received a kind of treatment, but after that, the roughness index remains steady as well.

\section{Discussion}

In this part, the results of each section mentioned in the previous part are evaluated and then at least the most two appropriate maintenance treatments suggested for each subsection.
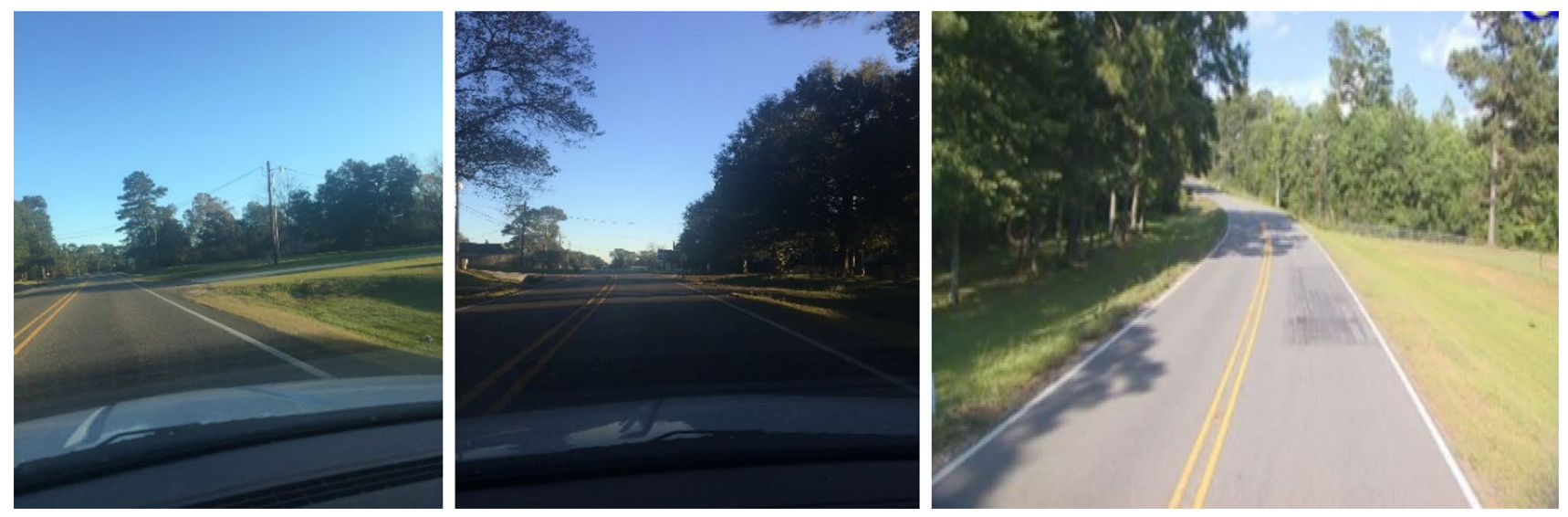

Fig. 11 Existing road conditions of LA 22

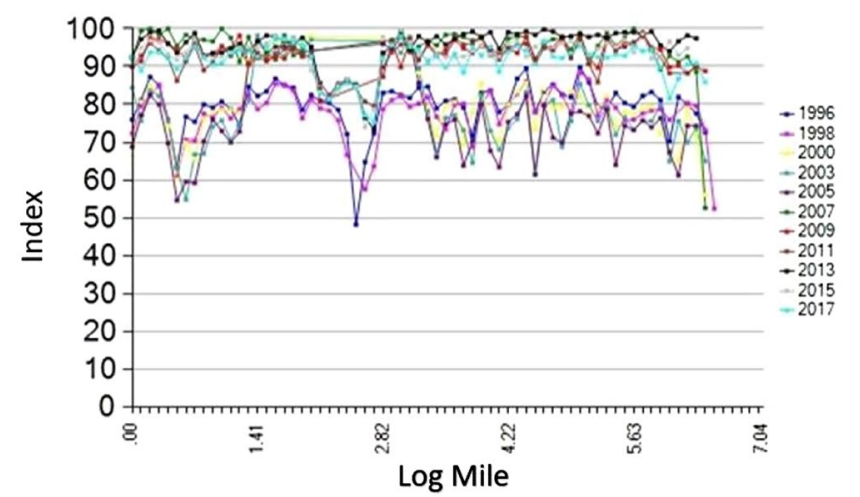

(a)

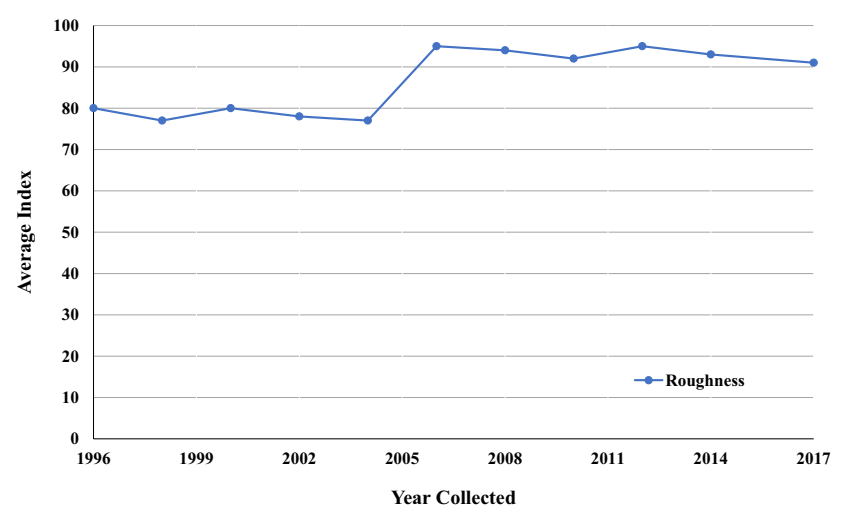

(b)

Fig. 12 Roughness index plot for control Section 260-05 a index plot along mile route b Yearly average index plot

Table 4 PMS Data for Control Section 260-03

\begin{tabular}{|c|c|c|c|c|c|c|c|c|c|c|}
\hline Sub-S. & Pave type & Lane mile & ADT & Rut index & Alligator index & Random index & Roughness index & $\mathrm{PCl}$ & Last year rehab & Last Rehab \\
\hline 1 & ASP & 10.615 & 4400 & 90.46 & 72.65 & 81.03 & 87.39 & 77.96 & 2000 & None \\
\hline
\end{tabular}




\subsection{Control section $260-02$}

As can be seen from Table 3, $\mathrm{PCl}$ for the whole sections is more than the $\mathrm{PCl}$ trigger value of $65 \%$, which consequently shows that the rehabilitation technique would utilize a pavement preservation technique for these road sections.

Table 4 indicates the weighting and scoring factors utilized for the control section and the subsequent final ranking for the selected alternatives. Sections 1 and 3 have low severity of alligator cracking plus roughness and random cracking issue, so Micro-surfacing and thin hot mix surface overlay would be suggested treatment. Sect. 2 seem to be in good condition, and the roughness problem is to be the major distress in the subsection, so sand seal, chip seal, and ultra-thin hot-mix overlay would be suggested treatments. For Sect. 4, the major distress will be alligator and roughness cracking and thin overlay, and Micro-surfacing would be suggested treatment. By assessing the multiple alternatives based upon the proposed analysis methodology, feasible alternatives ranked for each subsection.

\subsection{Control section 260-03}

As can be seen from Table 5, the subsection had a low PCl; however, it is higher than the trigger value (65\%). Consequently, preventive maintenance treatment was recommended. The relatively high rutting index in Table 5 suggests that the entire section did not experience such major rutting problems. However, this subsection had a low alligator index. Therefore, the average alligator index, which is an indication for the random cracks, was plotted along the control section between the years 1996 and 2017 to provide better insight into the nature of these cracks.

Table 6 indicates the weighting and scoring factors utilized for the control section, and by evaluating the multiple alternatives based upon the proposed analysis methodology, subsequent final ranking presented to be the feasible alternative for the subsection.

\subsection{Control section $260-04$}

As showed from Table 7, the subsection had a relatively low pavement condition $\mathrm{PCl}$ index. Rutting and random indexes are high, and there is no need to be considered in pavement maintenance; however, this section has a little random problem.

Based on PMS data and then the analysis that conducted for this control section, the best candidates to correct the only distress, which is roughness for this subsection and weighting and scoring factors plus ranked the feasible alternative for the subsection indicated in Table 8. 
Table 6 PMS Data for Control Section 260-05

\begin{tabular}{lllllllllll}
\hline Sub-S. & Pave type & Lane mile & ADT & Rut index & Alligator index & Random index & Roughness index & PCl & Last year rehab & Last rehab \\
\hline 1 & ASP & 1.35 & 2800 & 96.61 & 100 & 99.41 & 92.25 & 95.03 & 2007 & None \\
2 & ASP & 1.92 & 2800 & 98.75 & 99.07 & 99.19 & 94.56 & 96.29 & 2007 & None \\
3 & ASP & 2.17 & 4800 & 94.97 & 99.67 & 98.9 & 92.82 & 94.72 & 2007 & None \\
4 & ASP & 0.64 & 4800 & 92.28 & 100 & 100 & 91.78 & 88.94 & 2007 & None \\
5 & ASP & 0.381 & 2800 & 89.45 & 98.63 & 99.13 & 88.48 & 82.64 & 2007 & None \\
\hline
\end{tabular}

Table 7 Weighting, Scoring and Ranking Matrix for LA 16 \& 42

\begin{tabular}{|c|c|c|c|c|c|c|c|c|c|c|}
\hline \multicolumn{2}{|c|}{ Description } & \multirow{2}{*}{$\begin{array}{l}\text { Expected life } \\
20\end{array}$} & \multirow{2}{*}{$\begin{array}{l}\text { Pave. struc. } \\
10\end{array}$} & \multirow{2}{*}{$\begin{array}{l}\text { Exst. cond. } \\
10\end{array}$} & \multirow{2}{*}{$\begin{array}{l}\text { Initial cost } \\
20\end{array}$} & \multirow{2}{*}{$\begin{array}{l}\text { LCC } \\
20\end{array}$} & \multirow{2}{*}{$\begin{array}{l}\text { Traffic } \\
10\end{array}$} & \multirow{2}{*}{$\begin{array}{l}\begin{array}{l}\text { Ease of con- } \\
\text { struction }\end{array} \\
10\end{array}$} & \multirow[t]{2}{*}{ Total score } & \multirow[t]{2}{*}{ Rank } \\
\hline Sub & Alternatives & & & & & & & & & \\
\hline \multirow[t]{2}{*}{1,3} & Micro-surfacing & 12.0 & 9.0 & 7.0 & 20.0 & 20.0 & 6.0 & 9.0 & 83.0 & 1 \\
\hline & Thin Overlay & 20.0 & 8.0 & 7.0 & 5.8 & 9.3 & 9.0 & 8.0 & 67.1 & 2 \\
\hline \multirow[t]{3}{*}{2} & Chip seal & 8.9 & 9.0 & 7.0 & 20.0 & 20.0 & 6.0 & 9.5 & 80.4 & 1 \\
\hline & Sand seal & 11.1 & 9.0 & 8.0 & 9.1 & 9.4 & 7.0 & 9.5 & 63.1 & 2 \\
\hline & Ultra-Thin overlay & 20.0 & 8.0 & 7.0 & 4.6 & 5.5 & 9.0 & 8.0 & 62.1 & 3 \\
\hline \multirow[t]{2}{*}{4} & Micro-surfacing & 12.0 & 9.0 & 7.0 & 20.0 & 20.0 & 6.0 & 9.0 & 83.0 & 1 \\
\hline & Thin overlay & 20.0 & 8.0 & 7.0 & 5.8 & 6.7 & 9.0 & 8.0 & 64.4 & 2 \\
\hline
\end{tabular}

Table 8 Weighting, Scoring and Ranking Matrix for LA 22

\begin{tabular}{lllllllllll}
\hline Description & Expected Life & P. Struc. & Exst. cond. & Initial cost & LCC & $\begin{array}{l}\text { Traffic } \\
\text { Sub S. }\end{array}$ & Alternatives & 20 & $\begin{array}{l}\text { Ease of con- } \\
\text { struction }\end{array}$ & $\begin{array}{l}\text { Total score } \\
\text { Rank }\end{array}$ \\
\hline & Micro-surfacing & 12.0 & 10 & 10 & 20 & 20 & 10 & 10 & \\
& Thin overlay & 20.0 & 9.0 & 7.0 & 20.0 & 20.0 & 6.0 & 9.0 & 83.0 & 1 \\
\hline
\end{tabular}

Table 9 Weighting, Scoring and Ranking Matrix for LA 22

\begin{tabular}{llllllllll}
\hline Description & Expected Life & P. Struc. & Exst. cond. & Initial cost & LCC & Traffic & $\begin{array}{l}\text { Ease of con- } \\
\text { struction }\end{array}$ & $\begin{array}{l}\text { Total score } \\
\text { Rank }\end{array}$ \\
\hline Sub & Alternatives & 20 & 10 & 10 & 20 & 20 & 10 & 10 & \\
1 & Micro-surfacing & 12.0 & 9.0 & 7.0 & 20.0 & 20.0 & 6.0 & 9.0 & 83.0 \\
& Thin overlay & 20.0 & 8.0 & 7.0 & 4.8 & 10.3 & 9.0 & 8.0 & 67.1 \\
\hline
\end{tabular}

Table 10 Weighting, Scoring and Ranking Matrix for LA 22

\begin{tabular}{|c|c|c|c|c|c|c|c|c|c|c|}
\hline \multicolumn{2}{|c|}{ Description } & \multirow{2}{*}{$\begin{array}{l}\text { Expected life } \\
20\end{array}$} & \multirow{2}{*}{$\begin{array}{l}\text { P. Struc. } \\
10\end{array}$} & \multirow{2}{*}{$\begin{array}{l}\text { Exst. cond. } \\
10\end{array}$} & \multirow{2}{*}{$\begin{array}{l}\text { Initial cost } \\
20\end{array}$} & \multirow{2}{*}{$\begin{array}{l}\text { LCC } \\
20\end{array}$} & \multirow{2}{*}{$\begin{array}{l}\text { Traffic } \\
10\end{array}$} & \multirow{2}{*}{$\begin{array}{l}\begin{array}{l}\text { Ease of con- } \\
\text { struction }\end{array} \\
10\end{array}$} & \multirow[t]{2}{*}{ Total score } & \multirow[t]{2}{*}{ Rank } \\
\hline Sub & Alternatives & & & & & & & & & \\
\hline \multirow[t]{3}{*}{$1,2,3$} & Chip seal & 14.3 & 9.0 & 7.0 & 0.0 & 20.0 & 6.0 & 9.5 & 65.8 & 2.0 \\
\hline & Slurry seal & 14.3 & 9.0 & 8.0 & 0.0 & 15.7 & 7.0 & 9.5 & 63.5 & 3.0 \\
\hline & Defer action & 20.0 & 9.0 & 7.0 & 20.0 & 4.4 & 6.0 & 9.0 & 75.4 & 1.0 \\
\hline \multirow[t]{3}{*}{4 and 5} & Micro-surfacing & 13.3 & 9.0 & 7.0 & 4.1 & 4.3 & 6.0 & 9.0 & 52.7 & 3.0 \\
\hline & Ultra-thin overlay & 20.0 & 8.0 & 7.0 & 4.6 & 5.3 & 9.0 & 8.0 & 61.9 & 2.0 \\
\hline & Chip seal & 11.1 & 9.0 & 7.0 & 20.0 & 20.0 & 6.0 & 9.5 & 82.6 & 1.0 \\
\hline
\end{tabular}




\subsection{Control section $260-05$}

It is clear from Table 9 that all subsections had PCI more than trigger value (65\%). Consequently, preventive maintenance treatment was highly recommended rather than any structural rehabilitation. The high rutting index in Table 9 suggests that the entire section did not experience any rutting problems. Sections 1, 2, and 3 had relatively low roughness index as the main problem and Sects. 4 and 5 have slightly low rutting index and roughness index..

Table 10 indicates the weighting and scoring factors utilized for the control section. In this study, suggested treatments for all subsections presented and by evaluating the multiple alternatives based upon the proposed analysis methodology, defer action with Micro-surfacing after 7 years, and Cheap seal chip seal seemed to be the feasible alternative for all subsections.

\section{Conclusions}

This study provides a step-by-step framework and general guidelines for the process of project evaluation and selecting a feasible rehabilitation/maintenance technique in flexible pavement. A case study conducted on four roads in Livingston parish in the state of Louisiana according to the mentioned framework. Extensive historical data was collected from the LaDOT-PMS database. The group then embarked on an initial site visit and conducted a primary field survey to identify distresses and come up with candidate treatments. The collected data was analyzed by the usage of a weighting and scoring matrix. The matrix ranked feasible treatment options by designating a score based on the expected life of the treatment option, pavement structure, existing conditions, initial cost, LCCA, traffic and ease of construction, and so on. The pavement treatment with the highest score based on the weighting and score matrix is the recommended treatment for that control section. According to conducted case study evaluation, Micro-surfacing and thin overlay found the most common techniques, which are according to the LaDOT common treatment selection strategy. Also, since PMS data may not be accurate as it is collected every 2 years in Louisiana, it is suggested to conduct visual inspection thoroughly.

Acknowledgements The author would like to express his thanks to Boateng K. Ampadu, Mostafiz Emtiaz, and Sujata Subedi from Louisiana State University for providing valuable help and also show appreciation to Dr. Louay N. Mohammad, Dr. Samuel B. Cooper, Jr. and Chris Fillastre in Louisiana Transportation Research Center (LTRC) for providing PMS data and their kind help.

\section{Compliance with ethical standards}

Conflict of interest The corresponding author states that there is no conflict of interest.

\section{References}

1. Moazami D, Muniandy R, Hamid H, Yusoff Z (2010) Developing a comprehensive pavement management system in Tehran, Iran using microPAVER. J Geotech Eng 15:1782-1792

2. Wang LB, Park J, Hill SH (2005) Use of pavement management system data to monitor performance of pavements under warranty. Transp Res Rec J Transp Res Board 1940(1):21-31

3. Irfan M, Muhammad B Khurshid, Labi Samuel, Flora W (2010) Evaluating the cost effectiveness of flexible rehabilitation treatments using different performance criteria. J Transp Eng 135(10):753-763

4. Zaniewski JP, Mamlouk MS (1996) Pavement preventive maintenance: key to quality highways. J Transp Res Board. https://doi. org/10.3141/1680-04

5. Hall KT, Correa CE, Carpenter SH, Elliott RP (2001) Rehabilitation strategies for highway pavements. Final Report, NCHRP Proj 35:1-38

6. Shahin MY (2011) Pavement management for airports, roads, and parking lots. Springer, New York, NY

7. ASTM D6433-18 (2018) Standard practice for roads and parking lots pavement condition index surveys

8. Gallego E, Moya M, Piniés M, Ayuga F (2008) Valuation of low volume roads in Spain. Part 2: methodology validation. Biosyst Eng 101(1):135-142

9. McPherson EG, Muchnick J (2005) Effects of street tree shade on asphalt concrete pavement performance. J Arboric 31(6):303-310

10. Mishalani RG, Gong L (2009) Optimal infrastructure condition sampling over space and time for maintenance decision-making under uncertainty. Transp Res Part B Methodol 43(3):311-324

11. Scullion T (2001) Selecting rehabilitation options for flexible pavements: guidelines for field investigations. Texas Department of Transportation, Report no FHW A/fX-0111712-4

12. Labuz J, Dai S, Skok E, and Lukanen E (2008) Pavement rehabilitation selection. Minnesota Department of Transportation, Report no MN/RC 2008-06

13. Elbagalati O, Elseifi M, Gaspard K, Zhang Z (2018) Development of the pavement structural health index based on falling weight deflectometer testing. Int J Pavement Eng 19(1):1-8

14. GoogleEarth, 2019 https://www.google.com/maps/place/lowa.,

15. MJ Khattak, GY Baladi, X Sun, J Veazey, and C Landry 2007 Development of uniform sections for PMS inventory and application

16. Mohammad LN. Pavement evaluation and rehabilitation, Louisiana State University, CE7701

17. Louisiana Department of Transportation and Development (2016) Louisiana standard specifications for roads and bridges. Baton Rouge, LA

18. Louisiana 2017 IDEA-Overview. [Online]. Available: https:// www.appliedpavement.com/hosting/louisiana/pavement-inspe ction/pci-review/overview.html. (Accessed: 07-Dec-2019)

19. Khattak MJ, Baladi GY (2015) Development of cost effective treatment performance and treatment selection models. Project no FHWA/LA. 13/518, LTRC Project Number: 10-4P

20. Jamal Khattak M, Alrashidi M (2013) Performance of preventive maintenance treatments of flexible pavements. Int J Pavement Res Technol 6(3):184-196 
21. Khattak MJ, Baladi GY, Zhang X (2009) Development of index based pavement performance models for pavement management system (PMS) of LADOTD. Project no FHWA/LA.08/460

22. Hicks RG, Seeds SB, Peshkin DG (2000) Selecting a preventive maintenance treatment for flexible pavements. Transp Res Record 1680(1):1-12

23. "Asphalt Seal-Coat Treatments." [Online]. Available: https://www. fs.fed.us/eng/pubs/html/99771201/99771201.htm. (Accessed: 25-Nov-2019)

24. Lawrence M, Hachey A, Bahar G, and Frank G 2018 Highway safety benefit-cost analysis guide," Rep. No. FHWA-SA-18-001, p. Federal Highway Administration Office of Safety
25. Walls J III, Smith MR (1998) Life-cycle cost analysis in pavement design. Pavement Division Interim Technical Bulletin. Publication No. FHWA-SA-98-079

26. Bektas F, Smadi OG, Al-Zoubi M (2014) Pavement management performance modeling: evaluating the existing $\mathrm{PCl}$ equations. lowa State University (InTrans Project 13-455)

Publisher's Note Springer Nature remains neutral with regard to jurisdictional claims in published maps and institutional affiliations. 